\title{
DUBNA CYCLOTRONS - STATUS AND PLANS
}

\author{
B.N. Gikal", S.L. Bogomolov, S.N. Dmitriev, G.G. Gulbekyan, M.G. Itkis, \\ V.V. Kalagin, Yu.Ts. Oganessian, V.A. Sokolov
}

\section{Joint Institute for Nuclear Research, Dubna, Moscow region, Russia}

\section{Abstract}

In Laboratory of nuclear reactions there are 4 accelerators of heavy ions. Cyclotrons $\mathrm{U}-400, \mathrm{U}-400 \mathrm{M}$, $\mathrm{U}-200$ and DC-40 accelerate ions from P up to Bi with energy from 3 up to $100 \mathrm{MeV} /$ nucleon with high intensity. The large program of scientific and applied researches is carried out on the beams of heavy ions. In Laboratory the project DRIBs allowing obtaining beams of the accelerated radioactive ions is being realized. The first experiments on $6 \mathrm{He}$ and $8 \mathrm{He}$ beams are carried out.

\section{INTRODUCTION}

The FLNR scientific program on heavy ion physics included experiments on the synthesis of heavy and exotic nuclei using ion beams of stable and radioactive isotopes and studies of nuclear reactions, acceleration technology and applied research.

Presently Flerov Laboratory of Nuclear Reactions of Joint Institute for Nuclear Research has four cyclotrons of heavy ions, U-400, U-400M, U-200, DC-40, which provide performance of the basic and applied researches. Total operating time of cyclotrons is about 8000 hours/ year.

The intensive beams of ${ }^{48} \mathrm{Ca}$ ions on the cyclotron U400 have provided performance of the program on synthesis of a number of new isotopes of the superheavy elements.

The Tritium beam with the energy of $19 \mathrm{MeV} / \mathrm{n}$ and intensity of $10^{9}$ pps was accelerated on the cyclotrons U400. The beams of $\mathrm{He}^{6}(28 \mathrm{MeV} / \mathrm{n})$ and $\mathrm{He}^{8}(25 \mathrm{MeV} / \mathrm{n}$ with intensity $3 \cdot 10^{5}$ pps and $3 \cdot 10^{4}$ pps respectively were received in flight method using a thin Beryllium production target in the separation channel.

The realization of the project DRIBs (Dubna Radioactive Ion Beams) based on ISOL scheme is completed at the Laboratory. It will allow increasing the intensity of the $\mathrm{He}^{6}$ and $\mathrm{He}^{8}$ beams up to $10^{10}$ pps and $10^{8}$ pps respectively. The first physical experiment is being planned to carry out by the end of this year.

Last year the modernization of DC-40 cyclotron was carried out. The task of modernization is acceleration of an intensive beam of $\mathrm{Kr}$ with energy about $1.2 \mathrm{MeV} / \mathrm{n}$ that will be used for irradiation of deferent polymer materials.

FLNR works on creation of the cyclotron DC-72 for Slovak cyclotron center in Bratislava are being conducted. The accelerator is developed for acceleration of protons with energy up to $72 \mathrm{MeV}$ and heavy ions with energy from 3.5 up to $18 \mathrm{MeV} / \mathrm{n}$. The first beam is being planned to obtain in 2005 .

Flerov Laboratory of Nuclear Reactions in collaboration with Nuclear physics Institute (Almaty) the cyclotron DC-60 for applied researches has been developed for the Research Center at L.N.Gumilev Euroasia State University in Astana (Kazakhstan). The cyclotron is capable to accelerate ions from Carbon to Xenon with energies $0.35 \div 1.67 \mathrm{MeV} / \mathrm{n}$.

\section{THE U400 CYCLOTRON}

The U400 has 12 experimental channels, the main experimental setups are [1]: GFRS- gas filled recoil separator, VASILISSA- the electrostatic separator, CORSET/DEMON- the setup for study of fusion-fission reactions, U600- the setup for production the track membranes, MSP144- the magnetic separator.

The diagram of U-400 operation in 1997-2004 and using the beams is shown Figure 1. In 1998-2004, the $\mathrm{U} 400$ was mainly used for experiments with ${ }_{48} \mathrm{Ca}^{5+}$ ions for the purpose of synthesis the new super heavy elements.

The isochronous U400 cyclotron has been in operation since 1978 [2]. Until 1996, the PIG- ion source has been used for ion production. Since 1996, the ECR-4M ion source (made in GANIL, France) has been installed at the U400. The axial injection system was created to inject ions from the ECR-4M to the U400 center [3]. To increase the capture into acceleration the sine and linear bunchers were installed into the axial injection canal [4].

The essential modernization of the U400 axial injection in 2002 included sharp shortening of the horizontal part of the injection canal [5]. To increase the capture in acceleration efficiency, the combination of line and sine bunchers are used [6]. The linear buncher is situated at $4.4 \mathrm{~m}$ and the sine one is placed at $0.8 \mathrm{~m}$ above the median plane.

The modernization gave us the possibility to increase the ${ }_{48} \mathrm{Ca}^{+5}$ current into the injection line from $40 \div 60$ to $80 \div 100 \mu \mathrm{A}$ at the similar capture in acceleration efficiency. Correspondingly, the average output ${ }_{48} \mathrm{Ca}^{+18}$ ion current was increased from 15 to $25 \mu \mathrm{A}$.

The average intensity of ${ }_{48} \mathrm{Ca}^{+5}$ ions at the $\mathrm{U} 400$ extraction radius is about $4.3 \mathrm{p} \mu \mathrm{A}(21.5 \mu \mathrm{A})$. The typical ${ }_{48} \mathrm{Ca}^{+5}$ ion energy is $250 \div 270 \mathrm{MeV}$. Since 2003 , the TOF method [7] with two capacitive pickup electrodes has been used at the U400 to measure the extracted ion energy and to adjust the ion acceleration regime. 


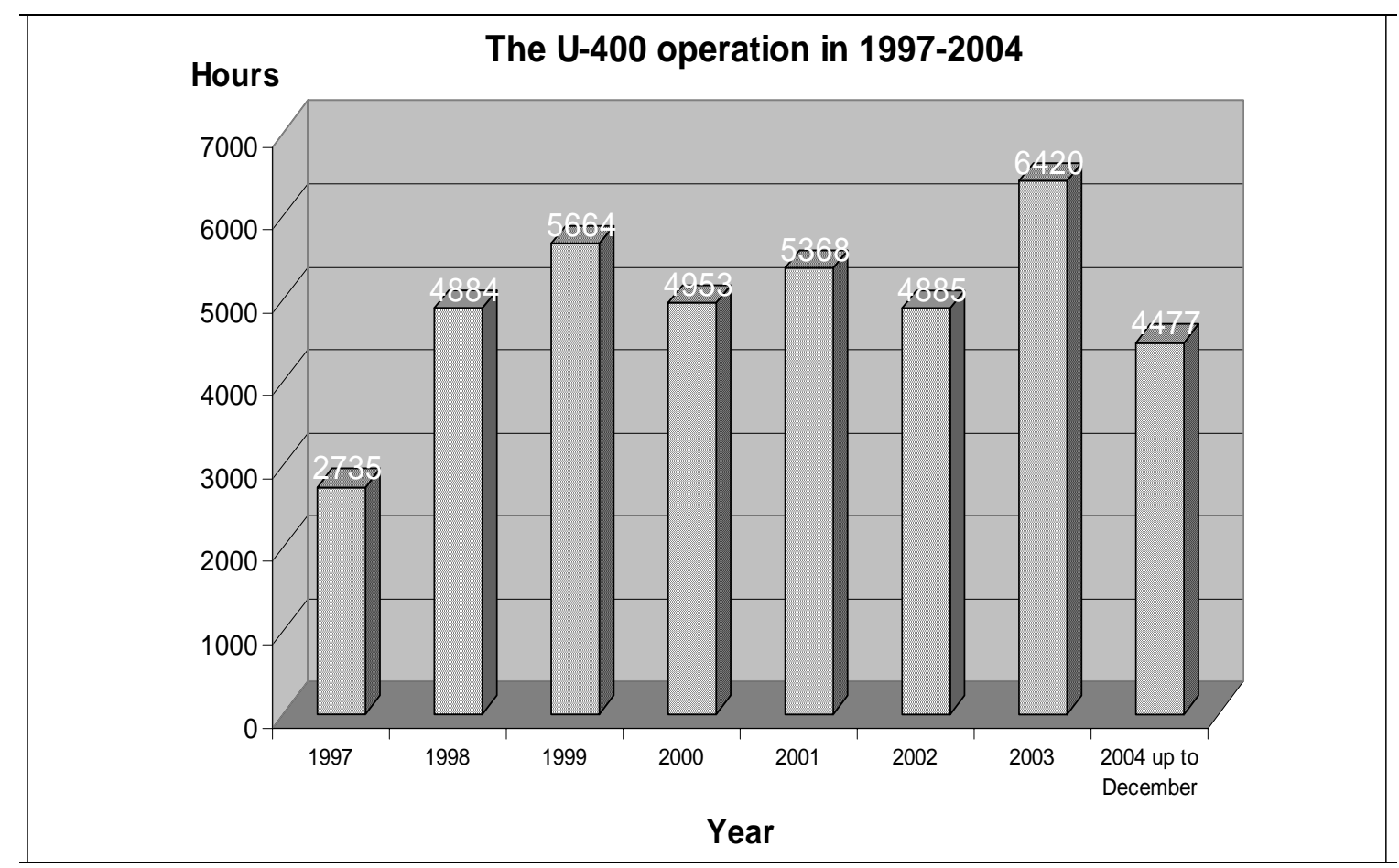

Figure 1: The diagram of U-400 operation in 1997-2004

The required energy of extracted ions received by means of changing the charge of accelerated particle (rough method) and by means of changing the stripping foil position, or changing the RF frequency and the magnetic field level (fluent method). To realize the ${ }_{48} \mathrm{Ca}^{+5}$ ion extraction with energies more than $260 \mathrm{MeV}$ with keeping the beam intensity, the special magnetic channel has been constructed and situated at the hill outer edge. The aim of the channel is additional focusing of the extracted ion beam at the second turn after the stripping foil, when the foil is moved to the big radius.

In experiments on synthesis the new super heavy elements, the average intensity of the ${ }_{48} \mathrm{Ca}^{+18}$ before the experimental target is about $1.4 \mathrm{p} \mu \mathrm{A}(25 \mu \mathrm{A})$. The main ${ }_{48} \mathrm{Ca}^{+18}$ line of the ion spectrum after the stripping foil is mainly used for the physical experiments. The results of ${ }_{48} \mathrm{Ca}$ acceleration in 2003 presented in [8]. In the regimes, the average consumption of solid ${ }_{48} \mathrm{Ca}$ is about $0.8 \mathrm{mg} /$ hour.

- $\mathrm{I}_{\Sigma}=8,2 \cdot 1014 \mathrm{pps}$

- Matter consumption $-0,8 \mathrm{mg} /$ hour

- Utilization - 0,16 mg/hour (20\%)

- $\quad 48 \mathrm{Ca}$ enrichment (60\% in matter)

- $\mathrm{dN} / \mathrm{dt}(48 \mathrm{Ca})=12 \cdot 10^{14} \mathrm{pps}(0,4 \mathrm{mg} /$ hour $)$

- $\quad$ Efficiency $\varepsilon 0-\mathrm{n} \approx 65 \%$

- $\quad$ Efficiency $\varepsilon 0-5+=10 \%$

\section{MODERNIZAION OF THE U400 CYCLOTRON AT THE FLNR JINR}

The modernization of the $\mathrm{U} 400$ has been suggested to improve the cyclotron parameters.

The aims of the modernization are:

1. Decreasing the magnetic field level at the cyclotron center from the region of $1.93 \div 2.1 \mathrm{~T}$ to $0.8 \div 1.8 \mathrm{~T}$, that allows us to decrease the electrical power of the U400R main coil power supply in four times.

2. Providing the fluent ion energy variation at factor 5 for every mass to charge ratio $\mathrm{A} / \mathrm{Z}$ at accuracy of $\Delta \mathrm{E} / \mathrm{E}=5 \cdot 10^{-3}$;

3. Increasing the intensity of accelerated ions of rare stable isotopes at factor 3 .

The beginning modernization of the U400 axial injection included sharp shortening the injection canal horizontal part. As the result, the distance from the ECR to the AM90 bending magnet became equal to $730 \mathrm{~mm}$. The changes allows us to increase the ${ }_{48} \mathrm{Ca}^{+18}$ ion intensity at the U400 output from 0.9 to $1.4 \mathrm{p} \mu \mathrm{A}$. Further modernization intends decreasing ion losses by means of increasing the SL solenoid inner diameter from 68 to $100 \mathrm{~mm}$ and the AM90 bending magnet horizontal aperture from 70 to $94 \mathrm{~mm}$.

In the future, we are planning to search possibility of increasing the injection voltage from the range of $13 \div 20 \mathrm{kV}$ to $40 \div 50 \mathrm{kV}$. As we estimated, the changes can give us increasing the U400R accelerating efficiency in $1.5 \div 2$ times, it is particularly important for ${ }_{48} \mathrm{Ca}$ ions. 
To extract ions out of the U400R we suppose to use two ways: electrostatic deflector and stripping foil method.

Both the methods allow us to extract ions in the directions of the existing ion transport channels.

The RF system of U400R will consists of two RF generators that will excite two separated RF dee resonators. The RF resonators will be made from iron with copper coating to decrease the outgassing rate from the vacuum surface.

The modernization of vacuum system will include changing five diffusion pumps VA-8-7 with $\mathrm{N}_{2}$ pumping rate of $\mathrm{Q}=4250 \mathrm{l} / \mathrm{s}$ each to five cryopumps with $\mathrm{Q}=3000 \mathrm{l} / \mathrm{s}$ each and two turbopumps with 1900 $1 / \mathrm{s}$ each. In addition the materials of the cyclotron vacuum chamber and RF resonators will be changed to decrease their outgassing rate. The given changes allow us to improve vacuum in the cyclotron chamber from $(1.5 \div 2) \times 10^{-7}$ Torr to $10^{-7}$ Torr.

\section{THE U400M CYCLOTRON}

The axial injection system of the U-400M [9] was put into operation in 1995. The design of the axial injection system of the U-400M cyclotron is similar to that of the U-400 cyclotron, but on cyclotron two sources of ions are installed: ECR - for production of heavy ions and high-frequency source of ions, which in our case was used for generation of Tritium ion beam.

The DECRIS-2 (Dubna ECR Ion Source) installed at the cyclotron is created at the FLNR [10]. The beam is focused by a lenses and three solenoids placed in the axial channel. The channel is pumped out by two turbomolecular and three cryogenic pumps, which provide vacuum of $2.5 * 10^{-7}$ Torr.

Due to good vacuum in the cyclotron chamber (better than $1 * 10^{-7}$ Torr) and high acceleration rate, the beam loss during the process of acceleration up to the final radius is less than $10 \%$.

The diagram of U-400M operation in 1997-2004 and using the beams is shown in Figure 3.

\section{BEAM EXTRACTION FROM U-400M CYCLOTRON}

The beam is extracted from the cyclotron by a stripping on a thin foil. The beam extraction system allows the beam to be extracted with a stripping ratio $Z_{\text {int }} / Z_{\text {ext }}=1.4 \div 1.7\left(Z_{\text {int }}\right.$ - the charge of ions of the internal beam, $Z_{\text {ext }}$ - the charge of ions of the extracted beam). The modernized this year extraction system provides a beam extraction efficiency of $70-80 \%$.

The beam is extracted from the cyclotron by a stripping foil. The beam extraction system allows the beam to be extracted with a stripping ratio $Z_{\text {int }} / Z_{\text {ext }}=$ $1.4 \div 1.7\left(Z_{\text {int }}\right.$ - the charge of ions of the internal beam, $Z_{\text {ext }}$ - the charge of ions of the extracted beam). Main ion energy range of extracted ions is $30 \div 50 \mathrm{MeV} / \mathrm{n}$. The beam extraction efficiency constitutes of $70-80 \%$.
At present a number of new set-ups have been mounted, including the ACCULINNA [11] channel, intended for the production of radioactive ion beams. To carry out these experiments, the ECR source has been specially adjusted, which has enabled the production of high intensity beams of light ions both of gaseous and solid materials.

The intensity of beams of light ions in the range from Li to $\mathrm{Ne}$ with an energy of $30 \div 50 \mathrm{MeV} /$ nucl was $3 \div 5 * 10^{13}$ pps. This was achieved with using a bunching system, which increases the intensity of the beam by a factor of $3 \div 5$. Table 1 shows the efficiency of the beam transportation from the ECR source to the physical target obtained for ${ }^{11} \mathrm{~B}^{3+}$.

Table 1: The efficiency of the ${ }^{11} \mathrm{~B}^{3+}$ beam transportation from the ECR source to the physical target.

\begin{tabular}{|c|c|c|c|c|}
\hline $\mathrm{I}_{\mathrm{ECR}}$ & $\begin{array}{c}\mathrm{I}, \\
\text { in the } \\
\text { center }\end{array}$ & $\begin{array}{c}\mathrm{I}, \\
\text { at final radius }\end{array}$ & $\begin{array}{c}\mathrm{I}, \\
\text { extracted }\end{array}$ & $\begin{array}{c}\mathrm{I}, \\
\text { on the } \\
\text { target }\end{array}$ \\
\hline${ }^{11} \mathrm{~B}^{3+}$ & ${ }^{11} \mathrm{~B}^{3+}$ & ${ }^{11} \mathrm{~B}^{3+}$ & ${ }^{11} \mathrm{~B}^{5+}$ & ${ }^{11} \mathrm{~B}^{5+}$ \\
\hline $86 \mathrm{e} \mu \mathrm{A}$ & $22 \mathrm{e} \mu \mathrm{A}$ & $20 \mathrm{e} \mu \mathrm{A}$ & $30 \mathrm{e} \mu \mathrm{A}$ & $30 \mathrm{e} \mu \mathrm{A}$ \\
\hline $1.7 \cdot 10^{14} \mathrm{pps}$ & $4.4 \cdot 10^{13} \mathrm{pps}$ & $4 \cdot 10^{13} \mathrm{pps}$ & $3.6 \cdot 10^{13} \mathrm{pps}$ & $3.6 \cdot 10^{13} \mathrm{pps}$ \\
\hline \multicolumn{3}{|c|}{$90 \%$} & & \\
\hline & $26 \%$ & & $90 \%$ \\
\hline & & $21 \%$ & \\
\hline & &
\end{tabular}

\section{TRITIUM ACCELERATION}

The tritium ion beam was required for study of ${ }^{4} \mathrm{H}$ and ${ }^{5} \mathrm{H}$ resonance states in neutron transfer reactions $\mathrm{t}+\mathrm{t} \rightarrow{ }^{5} \mathrm{H}+\mathrm{p}$ and $\mathrm{t}+\mathrm{t} \rightarrow{ }^{4} \mathrm{H}+\mathrm{d}$. Experiments were performed at the separator ACCULINNA [11].

At the U400M cyclotron the tritium ions should be accelerated as molecular ions (DT) ${ }^{+}$from the point of view beam extraction by stripping. The required beam intensity on the liquid tritium target was about $10^{8} \mathrm{pps}$. Taking into account the beam losses on transport and monochromatisation the intensity of the accelerated beam should be about $10 \mathrm{nA}\left(610^{10} \mathrm{pps}\right)$.

The main requirements to the ion source were:

- minimal consumption of radioactive tritium;

- high output of molecular ions;

- long lifetime.

For production of molecular ions the RF ion source was chosen. During the operation at the test bench the ion source was optimized for production of $\mathrm{H}_{2}{ }^{+}$ions.

The schematic view of the RF ion source with electrostatic optics is shown in Figure2.

For feeding of the tritium atoms into the ion source the special gas feed system was developed in RFNC VNIIEPh (Sarov, Russia) that provides fine regulation of gas flow and safety handling with tritium. The system has two channels for the gas feed - one was used for feeding of deuterium-tritium mixture with the 
tritium content of $1 \%$, and the second - for the main gas - deuterium.

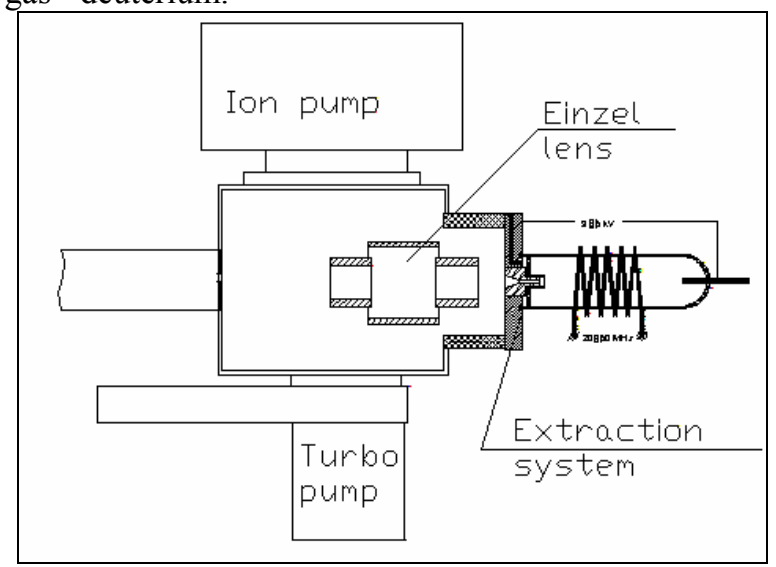

Figure 2: The schematic view of the RF ion source.

A beam of $58-\mathrm{MeV}$ tritons was obtained from the U$400 \mathrm{M}$ cyclotron and delivered to the tritium target. The ACCULINNA separator ion optics was used to select the beam having an energy spread smaller than $0.5 \%$, angular dispersion of $\Delta \theta<0.5^{\circ}$ and a $4-\mathrm{mm}$ beam spot in the final focus plane. The average intensity of the delivered beam was around $2 \times 10^{7} \mathrm{~s}^{-1}$ [12]. Table 2 shows the efficiency of the tritium beam transportation from the ion source to the physical target.

All together, the beam quality, target parameters and performance of detector telescopes, allow one to have an experimental resolution of $\sim 500 \mathrm{keV}$ for the widths of ${ }^{5} \mathrm{H}$ resonance states which could result from the $t+t$ reaction.
Table 2: Efficiency of acceleration and extraction of tritium ion beam.

\begin{tabular}{|c|c|c|c|}
\hline $\mathbf{I}_{\mathrm{is}}, \mathbf{n A}$ & $\mathbf{I}_{\text {int }}, \mathbf{n A}$ & $\mathbf{I}_{\text {ext }}, \mathbf{n A}$ & $\mathbf{I}_{\text {target }}, \mathbf{n A}$ \\
\hline 12 & 5 & 4,7 & 4,5 \\
\hline \multicolumn{2}{|c|}{$42 \%$} & & \\
\hline & \multicolumn{2}{|c|}{$94 \%$} & \\
\hline & & & \\
\hline
\end{tabular}

A series of experiments on the production of radioactive ion beams from $\mathrm{Li}$ to $\mathrm{O}$ with energy of $30 \div 50 \mathrm{MeV} /$ nucl was carried out at the ACCULINNA facility [11]. On the focal plane of the facility spots of ${ }^{6} \mathrm{He},{ }^{8} \mathrm{He},{ }^{11} \mathrm{Li},{ }^{12} \mathrm{Be}$ beams were about $10 \mathrm{~mm}$ in diameter, the ion energy spread $-\Delta \mathrm{E} / \mathrm{E}=5 \%$. The obtained results are presented in Table 3 .

Table 3. Radioactive ion beams produced by ACCULINNA facility at the Be target (primary beam intensity $-6.25 \cdot 10^{12} \mathrm{pps}$ ).

\begin{tabular}{|c|c|c|}
\hline RIB, E RIB & Yields, pps & Reaction \\
\hline${ }^{6} \mathrm{He}(25 \mathrm{MeV} / \mathrm{A})$ & $9.0 \cdot 10^{5}$ & $\begin{array}{c}\mathrm{Be}+{ }^{7} \mathrm{Li}(32 \\
\mathrm{MeV} / \mathrm{A})\end{array}$ \\
\hline${ }^{8} \mathrm{He}(25 \mathrm{MeV} / \mathrm{A})$ & $2.5 \cdot 10^{3}$ & $\begin{array}{c}\mathrm{Be}+{ }^{13} \mathrm{C}(43 \\
\mathrm{MeV} / \mathrm{A})\end{array}$ \\
\hline${ }^{11} \mathrm{Li}(35 \mathrm{MeV} / \mathrm{A})$ & $2.6 \cdot 10^{2}$ & $\begin{array}{c}\mathrm{Be}+{ }^{15} \mathrm{~N}(47 \\
\mathrm{MeV} / \mathrm{A})\end{array}$ \\
\hline${ }^{12} \mathrm{Be}(27 \mathrm{MeV} / \mathrm{A})$ & $1.3 \cdot 10^{4}$ & $\begin{array}{c}\mathrm{Be}+{ }^{18} \mathrm{O}(35 \\
\mathrm{MeV} / \mathrm{A})\end{array}$ \\
\hline
\end{tabular}

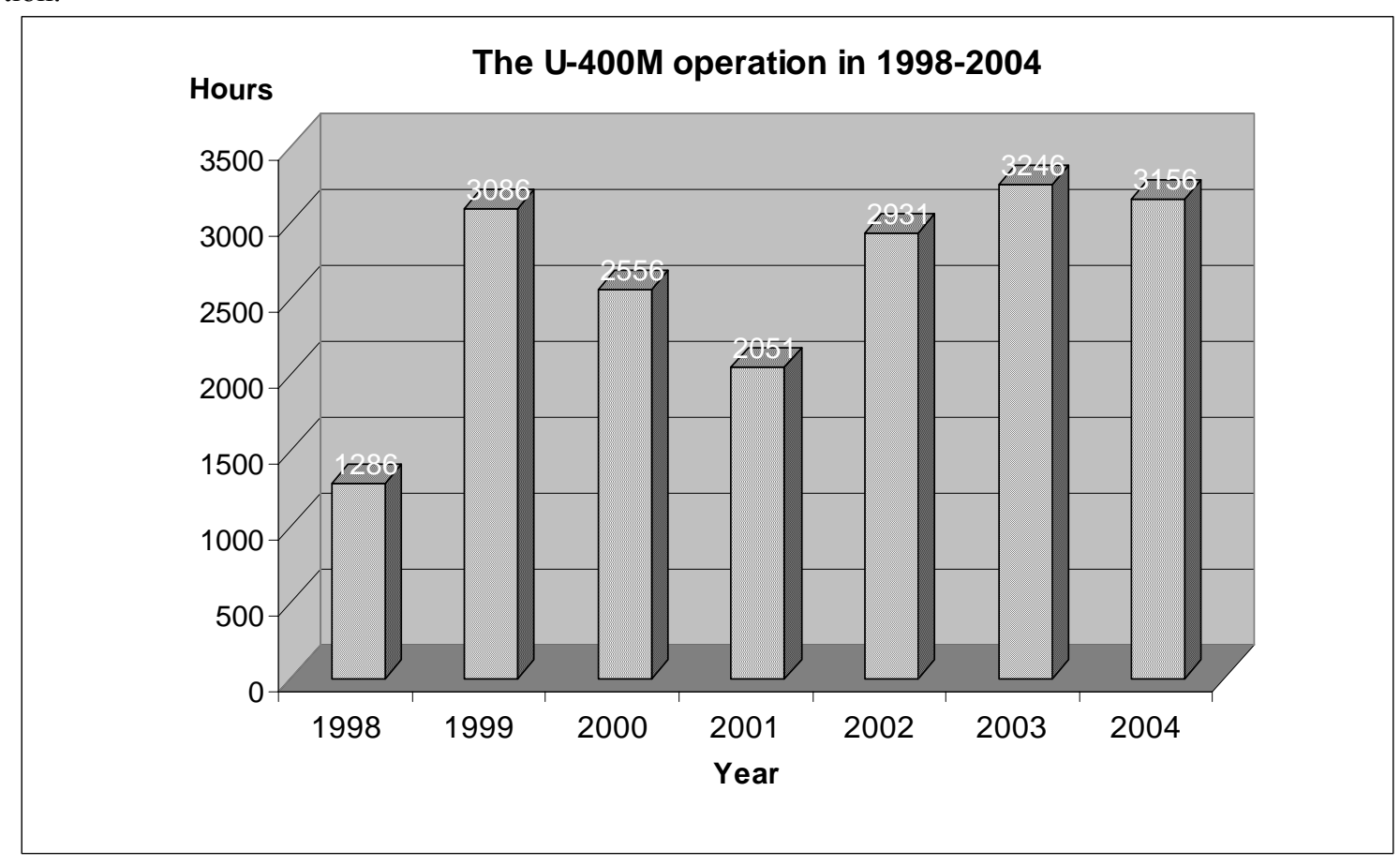

Figure 3: The diagram of U-400M operation in 1997-2004 
In $2000 \div 2002$ the first stage of the DRIBs project has been realized at the U400-U400M accelerator complex.

This year a series of experiments on ${ }^{6} \mathrm{He}$ ion beam will be started.

\section{REFERENCES}

1. "JINR FLNR Scientific report 1995-1996", Dubna (1997), “JINR FLNR Scientific report 1997-1998", Dubna (2000).

2. G. Gulbekian and CYCLOTRON Group, "Status of the FLNR JINR Heavy Ion Cyclotrons" in Proc. Of $14^{\text {th }}$ Int. Conf. On Cyclotrons and Their Applications, Cape Town, South Africa, 1995, p. 95.

3. Yu.Ts. Oganessian, G.G. Gulbekian, B.N. Gikal, M. El-Shazly et al., "Axial injection system for the U-400 cyclotron with the ECR-4M ion source", in JINR FLNR sci. rep.1995-1996, Heavy Ion Physics, Dubna 1997, p. 270.

4. O. Borisov, B. Gikal, G. Gulbekyan, I. Ivanenko, I. Kalagin, "Optimization of the axial injection system for U-400 cyclotron (linear buncher)", in Proc. of EPAC2000, Vienna, Austria, 2000, p. 1468.

5. Yu. Ts. Oganessian, G.G. Gulbekyan, B.N. Gikal, I.V. Kalagin et al. "Status of the U400 cyclotron at the FLNR JINR", in Proc. of APAC-2004 Conf., Gyeongju, Korea, 2004.

6. I.Kalagin, I. Ivanenko, G.Gulbekian "The experimental investigation of the beam transportation efficiency through the axial injection system of the U400 cyclotron", in Proc. of the 2001 Particle Accelerator Conf., Chicago, 2001, p. 1568.

7. Wolf B., "Handbook of ion sources", CRC Press, 1995.

8. Yu.Ts.Oganessian, http://flerovlab.jinr.ru/flnr.

9. G.G.Gulbekian, I.V.Kolesov, V.V.Bekhterev et al. "Axial injection system for the U-400M cyclotron with an ECR ion source" in JINR FLNR Sci. Rep.1993-1994, Heavy Ion Physics, Dubna 1995, p. 227.

10. A. Efremov, V. Behterev, S.L.Bogomolov, V.B.Kutner, A.N.Lebedev, V.N.Loginov, N.Yu.Yazvitsky "Performance of the ion source DECRIS-14-2”. Rev. Sci. Instrum. 69(2) (1998) 662.

11. Rodin A.M. et al., NIM B126 (1997) 236.

12. Yu.Ts. Oganessian, G.G.Gulbekian, S.L.Bogomolov et al. "Production and acceleration of tritium ion beam at the U-400M cyclotron", Proc. of the $16^{\text {th }}$ Int. Conf. On Cyclotrons and Their Applications, East Lansing, USA, ( 2001), p. 466. 